\title{
Arte y docencia: una composición lúdica
}

\author{
Nancy Araceli Galván Aguilar
}

\begin{abstract}
Resumen
Una de las actividades profesionales más gratificantes que he tenido la fortuna de practicar es la docencia universitaria. Ser profesora en la Facultad de Filosofía y Letras (FFyL) de la Universidad Nacional Autónoma de México (UnAm) significa, al mismo tiempo y en gran medida, reto y vocación, compromiso y apertura. No ha sido un camino sencillo, pero sí ha resultado una experiencia llena de aprendizajes en términos profesionales y, desde luego, personales. El objetivo de este este texto, por lo tanto, es narrar a modo de testimonio algunos de los aspectos más significativos que han permitido definir mi propio proceso como docente y establecer ciertos principios o ejes orientadores de mi práctica en el aula universitaria, destacando al arte como un recurso valioso para el aprendizaje. Si bien todas las artes poseen un gran potencial para los procesos de enseñanza y aprendizaje, en este artículo resaltaré las experiencias que he tenido con las artes visuales, específicamente en las posibilidades educativas de la fotografía.
\end{abstract}

Palabras clave: docencia universitaria, estrategias didácticas, arte y educación, fotografía.

\section{ARTS AND teACHING: a PLAYfUl COMPOSITION}

\begin{abstract}
One of the most rewarding professional activities I have had the fortune to practice is teaching in higher education. Being a professor at the Faculty of Philosophy and Letters (FFyL) of the National Autonomous University of Mexico (UNAM) has meant, at the same time and to a large extent, challenge and vocation, commitment and openness. It has not been a simple path, but it has been an experience full of learning in professional and personal terms. The objective of this article, therefore, is to narrate as a testimony some of the most significant aspects that have allowed me to define my own process as a teacher and to establish certain principles or guiding axes of my practice in the classroom, highlighting art as a valuable resource for learning. While all art forms have great potential in teaching and learning processes, in this article I will focus on the experiences I have had using visual arts, specifically, the educational possibilities of photography.
\end{abstract}

Keywords: teaching, higher education, learning strategies, arts and education, photography.

Dol: http://doi.org/10.22201/codeic.16076079e.2019.v20n6.a8 


\section{Nancy Araceli Galván Aguilar}

http://orcid.org/0000-0001-7666-4610 nancygalvan@comunidad.unam.mx

Profesora de Asignatura del Colegio de Pedagogía (FFyL-UNAm), responsable de dos grupos de las asignaturas Educación No Formal 1 y 2 y el Taller de Educación No Formal 3 y 4, dedicado este último al estudio de la Educación y la Cultura.

Jefa de Departamento del área de las Humanidades y las Artes, en la Subdirección de Planes y Programas de Estudio, de la Coordinación de Desarrollo Educativo e Innovación Curricular de la UNAM.

${ }^{1}$ Fragmento del "Testamento a jóvenes creadores", dictado por el escultor francés Auguste Rodin a Paul Gsell en 1911, para que fuera publicado después de su muerte. El texto completo puede leerse en el Tomo II de Histoire Générale de l'Art Francais de la Révolution à nos jours (Fontainas y Vauxcelles, 1922). La traducción de Soumaya Slim de Romero y Gabriela Huerta Tamayo puede consultarse en: https://es.wikisource.org/wiki/

Testamento a los jóvenes creadores.
“El mundo sólo será feliz cuando todos los hombres tengan almas de artistas, es decir, cuando todos hagan con placer su tarea".

Auguste Rodin

Durante casi quince años como profesora de asignatura en el Colegio de Pedagogía de la Facultad de Filosofía y Letras (FFyL) de la unAm, he transitado los ámbitos de la investigación pedagógica y de la educación no formal, combinando de diversas formas dos de mis pasiones: el arte y la docencia. La oportunidad de estar frente a grupo se presentó, de manera extraordinaria, al concluir el segundo semestre de la carrera en Pedagogía, cuando fui invitada por la Dra. Teresita Durán Ramos para participar en la clase de Iniciación a la investigación pedagógica, que ella impartía en los dos primeros semestres de la licenciatura. Fue así, mientras continuaba mis estudios, que descubrí el infinito gozo de la enseñanza en las aulas de la Facultad.

Por otro lado, también en esa época encontré en las clases de Educación extraescolar, de la Mtra. Glenda Cabrera Aquino, el fascinante mundo de la educación en museos como una opción laboral para los pedagogos. Mi primer empleo formal fue en este campo, aunque primero hice muchas horas de voluntariado como guía y tallerista para diferentes recintos como el Museo Soumaya, el Antiguo Colegio de San Ildefonso y el Museo Nacional de Antropología. 
Después, como profesora interina de la clase de Investigación, tuve el interés por incorporar aspectos relacionados con el arte como:

- Ejercicios de observación e interpretación que favorecieran el desarrollo de habilidades para el análisis, la explicación, el razonamiento, la argumentación y la comunicación oral y escrita de los estudiantes.

- Reflexiones sobre la figura del artista en comparación con la del investigador en términos de cualidades, objetivos, formas de trabajo, etcétera.

Con ello, me di cuenta de que la creatividad, comúnmente asociada a la producción de artistas o genios, era en realidad una habilidad atribuible a cualquier profesional; por lo cual, los pedagogos podríamos explorarla y ponerla en práctica con mayor ahínco.

Algunos años más tarde, comencé a impartir dos asignaturas sobre Educación no formal², en lugar de la clase de Investigación. Los objetivos de estos cursos, cuyo tipo es teórico-práctico, implican básicamente conocer, distinguir y valorar los alcances, ámbitos y agentes de la educación no formal para comprender el fenómeno educativo desde una perspectiva no escolarizada, con el fin de generar estrategias de intervención que promuevan la formación integral de las personas. En esta materia me ha resultado mucho más natural y oportuno introducir actividades relacionadas con el arte como recurso para estudiar, intervenir y modificar nuestro entorno desde lo educativo.

El arte, como medio para el aprendizaje, favorece la aproximación a temas como la educación ambiental, los derechos humanos, la ciudadanía incluyente, la perspectiva de género, la educación para la salud y la patrimonial, entre muchos otros; ya que no sólo lo hace desde su carácter teórico y conceptual, sino desde lo afectivo, lo emocional.

A continuación, expongo los principios o ejes teóricos que han servido como orientadores de mi práctica docente y de la dinámica que me gusta propiciar en el aula. No obstante, conviene señalar que dichas estrategias didácticas tienen su origen en el contexto de la educación no formal. Ésta, al ubicarse primordialmente en espacios no escolarizados, distan de buscar la acreditación o la graduación formal de un sistema educativo nacional (Pastor Homs, 2001); un ejemplo en el ámbito de las artes y la cultura sería el conjunto de programas, estrategias y acciones educativas que se implementan en los museos. Muchos de ellos pretenden que los visitantes aprendan sobre diversos temas como arte, historia o ciencia, desarrollen habilidades, actitudes y valores o generen hábitos

${ }^{2}$ Educación no formal 1 y 2, del quinto y sexto semestres, respectivamente, y el Taller de Educación no formal 3 y 4, del séptimo y octavo semestres, dedicado específicamente al ámbito de la educación y la cultura.

\section{La experiencia educativa y estética}

De mi experiencia en el campo de los museos he aprendido que cada sesión debe ser significativa para el grupo (incluyéndome) en términos de reflexión, discusión 
"Arte y docencia: una composición lúdica"

Nancy Araceli Galván Aguilar

Vol. 20, Núm. 6, noviembre-diciembre 2019

Revista Digital Universitaria

o puesta en práctica. Al menos así lo concibo en mi planeación o diseño. Para ello, busco que cada uno de los temas pueda vincularse con la historia de vida de los alumnos, para después reflexionar sobre tal fenómeno o situación a nivel local, nacional y mundial.

De este modo, cuando hablamos en clase de género, ecofeminismo - educación sexual, el punto de partida son los hábitos, acciones, reglas y expectativas que hay en casa, para con ello estudiar las realidades y los contextos macro. Considero fundamental pensar desde lo cotidiano, lo propio, lo emocional, pues he notado que así el vínculo y el compromiso con el grupo es distinto, más profundo. A partir de este nivel individual, se crea una mayor disposición para implicarnos, como grupo, en el tema de las actitudes y valores, los hábitos y las prácticas (Hooper-Greenhill, 2007).

Como referencia teórica en este aspecto, retomo, además, la concepción de John Dewey sobre la experiencia como ese fluir intencionado e integral de acontecimientos — sensoriales, cognitivos, emocionales-, que siguen su curso hasta una consumación satisfactoria de aprendizaje. Si bien, de manera cotidiana experimentamos el mundo gracias a la interacción con el entorno:

Las cosas son experimentadas, pero no de manera que articulen una experiencia. La distracción y la dispersión forman parte de nuestras vidas; lo que observamos y lo que pensamos, lo que deseamos y lo que tomamos, no siempre coinciden. [...] tenemos una experiencia cuando el material experimentado sigue su curso hasta su cumplimiento (fulfillment). Entonces y sólo entonces se distingue ésta de otras experiencias (Dewey, 1934, p. 41).

Como profesora aspiro a que cada clase resulte una experiencia significativa para los estudiantes, diferenciándose de otras actividades en términos de reflexión-acción. Probablemente, ésta sea una exigencia innecesaria o utópica, sin embargo, al reconocer que como docentes tenemos la oportunidad de generar procesos, ambientes y momentos educativos significativos en cuanto al impacto en la vida de nuestros estudiantes, no puedo evitar sentirme motivada y entusiasta al diseñar, planear e implementar diferentes estrategias de enseñanza.

Ahora bien, en cuanto a la experiencia estética, me parece oportuno recordar que para Plazaola (1991) se constituye a través de tres momentos; el primero es de asombro, esa "primera fase emotiva y estimulante, que es ruptura del ritmo cotidiano en que transcurre nuestro vivir pragmático" (p. 301). La siguiente etapa sería la contemplación del objeto que ha atrapado nuestra atención, en donde seremos transportados a otra dimensión por medio de la imaginación, conocimientos previos y nuestra propia (re)creación del objeto artístico, no el objeto real. En un tercer momento, para finalizar, se experimentaría el gozo que dicha contemplación nos ha provocado y que es un goce puro y desinteresado: "El placer desinteresado que la belleza nos procura no puede significar quedarnos indiferentes ante ella. La belleza es lo que hay de más 'interesante' bajo la luz del sol' (p. 309).

Desde mi perspectiva, el carácter estético de una experiencia educativa radica en la posibilidad tanto de enseñar como de aprender con asombro y 
detenimiento. Del mismo modo que una sola obra de arte puede llamar nuestra atención y conmovernos, dejando fuera distractores y la inmediatez con las que usualmente vivimos, se puede alcanzar cierto goce al final de la clase, que permita repensar o transformar nuestras ideas y posturas frente a los objetos y temas de estudio.

\section{Las posibilidades educativas del arte ${ }^{4}$}

Otro aprendizaje que he podido trasladar de la mediación con arte en museos hacia mi práctica docente implica disfrutar el proceso mismo de enseñanza y aprendizaje en el aula, así como su resultado. El momento de reflexión y discusión que ocurre cada clase se vuelve tan importante como los productos individuales o colectivos de final de unidad temática o semestre. Esto repercute, a su vez, en la forma de evaluar.

Por otro lado, los ejercicios con arte permiten crear un clima de confianza en el que todos puedan expresarse con libertad desde el inicio del curso. En la interpretación de una pintura o fotografía, por ejemplo, no hay una verdad única o correcta, todas las emociones e ideas son válidas e, incluso, entre más participaciones existan por parte de los alumnos, mayor será la comprensión del objeto de análisis.

Finalmente, en el arte he encontrado un medio para potenciar o favorecer habilidades como la creatividad, la comunicación, la colaboración, y la reflexión crítica; al igual que actitudes de respeto y empatía, útiles en el análisis de los fenómenos y hechos sociales.

\section{Las dimensiones del aprendizaje}

Reflexionar sobre el aprendizaje y sus implicaciones como docente es importante para favorecer el diseño de actividades y estrategias de evaluación acordes con lo que pretendo lograr al término de un curso. La propuesta descrita por Hooper-Greenhill (2007) ha sido fundamental en mi práctica, pues, en ella, se distingue un espectro amplio de posibilidades del aprendizaje (ver figura 1) en relación con las artes y la cultura. Desde esta perspectiva, las dimensiones en las que puede ocurrir el aprendizaje son: conocimiento y comprensión; habilidades/ competencias; comportamiento y progresión; disfrute, inspiración y creatividad; actitudes y valores. Cada una de ellas puede tener lugar y espacio a lo largo de

${ }^{4}$ En su libro El arte y la creación de la mente. El papel de las artes visuales en la transformación de la conciencia, Elliot Eisner dedica un apartado a lo que, desde su experiencia, la educación puede aprender de las artes (2004). Se sugiere consultarlo para más ideas y relaciones sobre este aspecto. las clases; igualmente.

En cuestión de evaluación, todas son importantes y tomadas en cuenta, tanto las actitudes y valores asociados con la empatía y el respeto, como la construcción de conocimientos y el desarrollo de habilidades demostrados durante el curso. 
Figura 1. Resultados genéricos de aprendizaje (generic learning outcomes), de la campaña Inspiring Learning for All. ${ }^{5}$
${ }^{5}$ Arts Council England. Inspiring Learning for All. Disponible en: https://www.artscouncil.org.uk/ advice-and-guidance/inspiringlearning-all-home-page

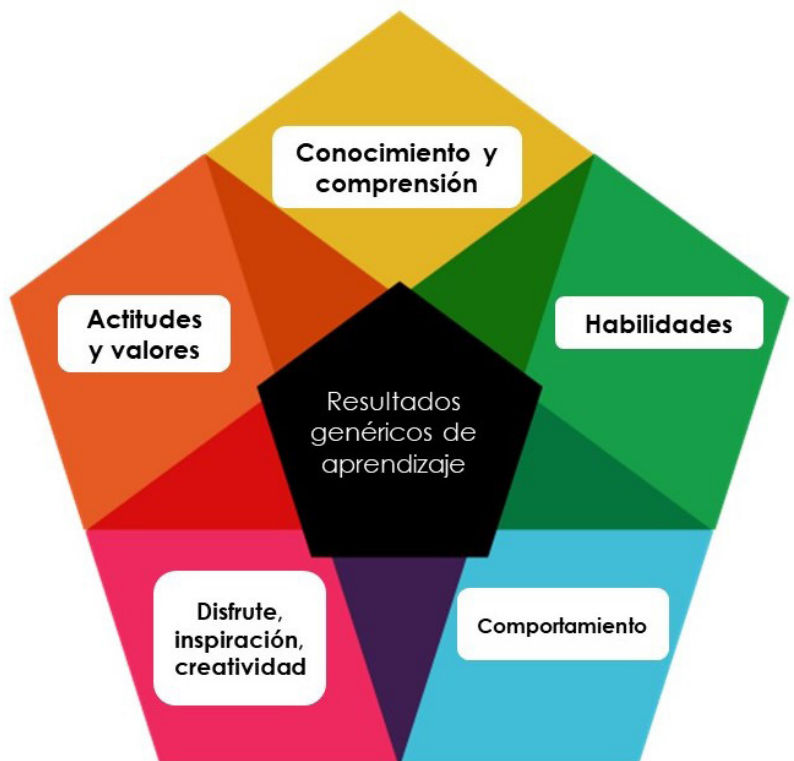

Los cuatro ejes descritos hasta este momento constituyen en gran medida el fundamento de mi práctica como docente para el diseño de experiencias educativas en el aula. A continuación, describiré brevemente algunas de las estrategias y actividades que he realizado utilizando la fotografía como recurso para explorar, reflexionar y proponer acciones de intervención pedagógica desde el aula.

\section{El arte como recurso en el aula universitaria}

Nuestra manera de conocer se ha transformado radicalmente desde la aparición de internety redes sociales, entre otras razones por la inmediatez que implican en la comunicación global; en consecuencia, el estudio de los fenómenos sociales ha requerido nuevas formas para entender y pensar al mundo. La fotografía, en este sentido, ha resultado un gran aliado en las clases para iniciar la reflexión sobre temas como la educación ambiental, la salud o los derechos humanos.

Un caso especial lo constituyen las fotografías de la artista visual Daniela Edburg, las cuales funcionan como un excelente medio para abrir la discusión en el aula. Sus originales composiciones llaman la atención por señalar el modo en el que nuestra vida dulce y confortable causa estragos irreversibles en nuestro entorno y en nuestra propia salud. El impacto de las imágenes siempre es fuerte para los estudiantes, quienes, a partir de observar y analizar, generan una dinámica abierta de discusión. Algunas de las fotografías que utilizo comúnmente son The mourning birds, Party girl, Atomic picnic, y la serie Drop dead gorgeous. Al igual que en una sala de exhibición en un museo, el uso de preguntas para empezar y mantener el diálogo es indispensable: ¿qué observan en la imagen?, ¿qué está ocurriendo?, ¿qué tipo de personajes/objetos/paisajes 
hay?, ¿qué emociones les transmite la fotografía?, ¿qué hábitos o prácticas de la vida cotidiana se representan?, ¿qué tan cercano es a tu cotidianidad?, etcétera.

Otra estrategia didáctica que utilizo con frecuencia consiste en la creación de un discurso visual en torno al tema educativo de interés del estudiante o del grupo. Desórdenes alimenticios, violencia doméstica, migración, maltrato infantil, violencia de género, formación de estereotipos, discapacidad, obsolescencia programada, entre otros, han sido algunos de los temas elegidos.

Mediante la fotografía, los estudiantes exploran y comparten miradas diversas de otros profesionales, que revelan realidades y contextos difícilmente palpables a través de textos y lecturas. Algunos de los trabajos fotográficos y artistas visuales que han sido utilizados para la generación de estos discursos son: Living with the enemy (Viviendo con el enemigo), de Donna Ferrato; Life can be a fairytale if you break the silence (La vida puede ser un cuento de hadas si rompes el silencio), de Alexsandro Palombo; leff Widener y Marc Riboud, con respecto a los movimientos sociales; Mike Anane y Kevin McElvaney, en torno al problema de la obsolescencia programada. A partir de las fotografías y su relación con los discursos teóricos, los estudiantes pueden experimentar una perspectiva más cercana y personal de los problemas, contextos y realidades que estudian durante la carrera y en los que posiblemente se desenvolverán como profesionales de la educación.

Un tercer y último ejemplo de cómo el arte puede ser un recurso transformador en el aula ha sido la realización de exposiciones museográficas. Éste es un proyecto grande que implica mucho trabajo colaborativo durante todo el semestre, pero la experiencia es completamente satisfactoria, volviéndose uno de los mejor aceptados por los estudiantes. Sin duda, se trata de un ejercicio que nos obliga a interactuar con actividades poco comunes dentro del campo de acción del pedagogo, o que por lo general se realizan desde otras disciplinas. Gestionar una exposición requiere la participación de todo el grupo, el común acuerdo, la toma de decisiones, y el trabajo comprometido de todos los equipos para lograr exhibir al final del semestre un discurso visual, el cual invite al diálogo con la comunidad universitaria. Uno de los casos más significativos fue la exposición fotográfica Cotidianidad-es CDMX (ver fotografías 1-7), cuyo objetivo, según lo descrito por los estudiantes en la cédula introductoria de la galería, fue:

invitar a detenerse y mirar lo que nos rodea: habitantes, jardines, arquitecturas, transportes y oficios; actitudes, valores y emociones [...]. A pensar de qué manera estos elementos ayudan a generar nuestra perspectiva de la realidad [...] nuestro andar es el reflejo de las prácticas diarias, que nos forman y transforman. Distinguir la cotidianidad del otro, lo ajeno a sí mismo, la otredad, dialogar a partir de otras identidades, de su construcción, de las diferentes formas de vida que hay en la ciudad.

Las fotografías exhibidas en la ffy L fueron capturadas por los propios estudiantes durante el semestre 2017-2. Cada semana se proponía un ángulo distinto de la Ciudad de México como naturaleza, mascotas, transportes, gente, oficios, amor, educación. Los estudiantes que participaron en dicho taller, además de 
Fotografía 1. "La magia existe" de Libier Madrigal, estudiante de Pedagogía Reforma, cDMx, octubre de 2014. problematizar temas de interés común, descubrieron en la fotografía un aliado para expresarse, representar, identificar, destacar, y evocar sus ideas.
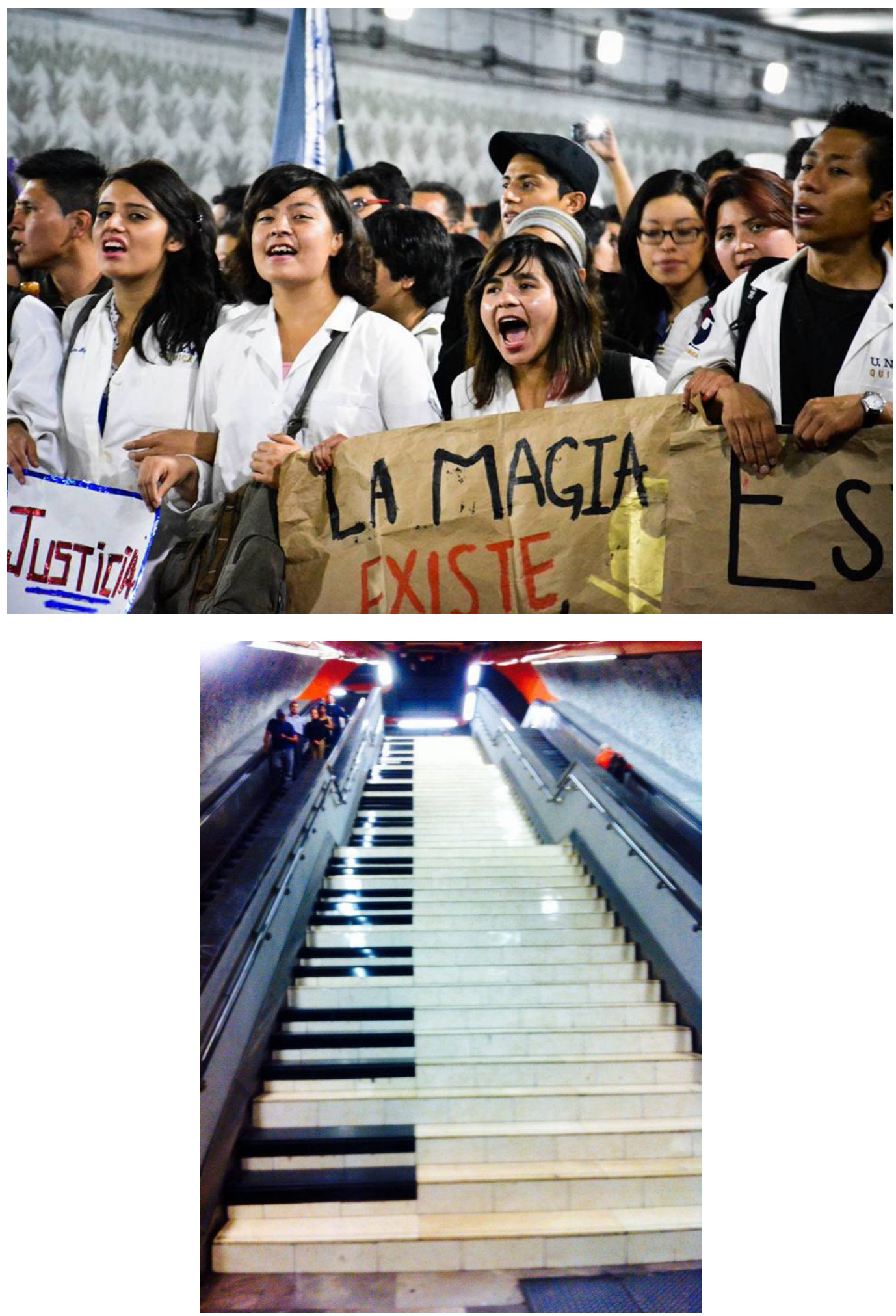

Fotografía 2. "Escaleras musicales" de Fabiola Godoy Flores, estudiante de Pedagogía. Metro Polanco, cDmx, marzo de 2017. 
Fotografía 3. "Nunca es tarde para aprender" de Brenda Martínez, estudiante de Pedagogía.

Zapotitlán, Tláhuac, cdmx, enero de 2017.

Fotografía 4. "La vida es 10\% lo que haces y $90 \%$ como te lo tomas" de Axayacatl Medina Ramos, egresado de Ingeniería. Av. Insurgentes, CDMX, junio de 2016.
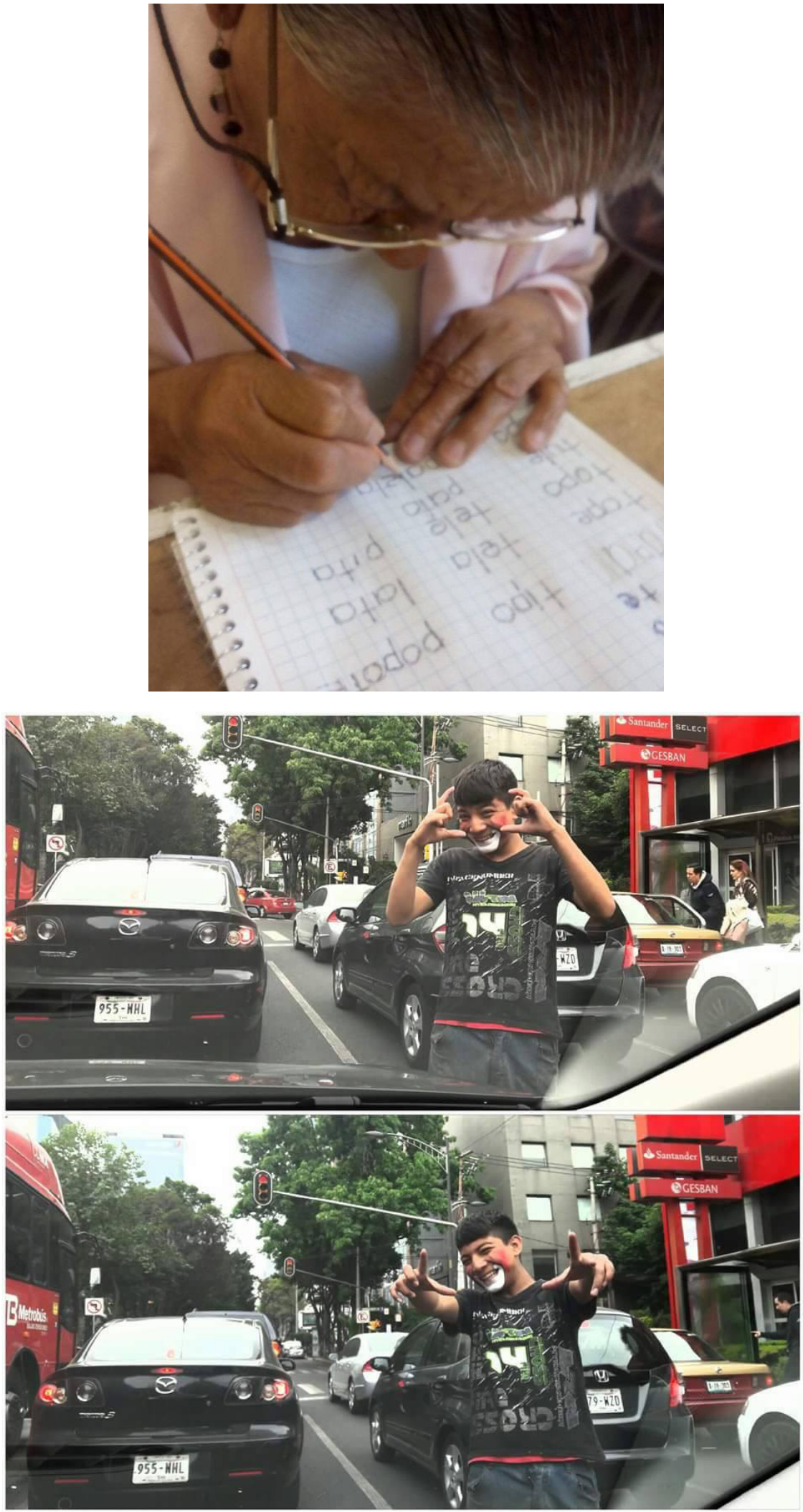
Fotografía 5. Proceso de selección de imágenes y creación de discurso visual. Salón 2-2 del Anexo de la Facultad de Filosofía y Letras,
Cabe resaltar que en este tipo de proyectos se introducen actividades relacionadas con la curaduría para la creación del discurso expositivo: sobre qué se va a hablar y cómo se va a decir, desde dónde, desde qué referentes o posturas; la museografía, cómo exhibir las obras: el montaje propiamente, de acuerdo con el lugar de exhibición; y el diseño gráfico, para la elaboración de materiales de difusión como las invitaciones y la comunicación en redes sociales, además de la identidad gráfica de la propia exposición. En este sentido, la experiencia se vuelve valiosa porque los estudiantes pueden conocer procesos y retos de otras actividades y oficios para que, de manera interdisciplinaria, pueda lograrse un proyecto complejo como el de una exposición fotográfica.

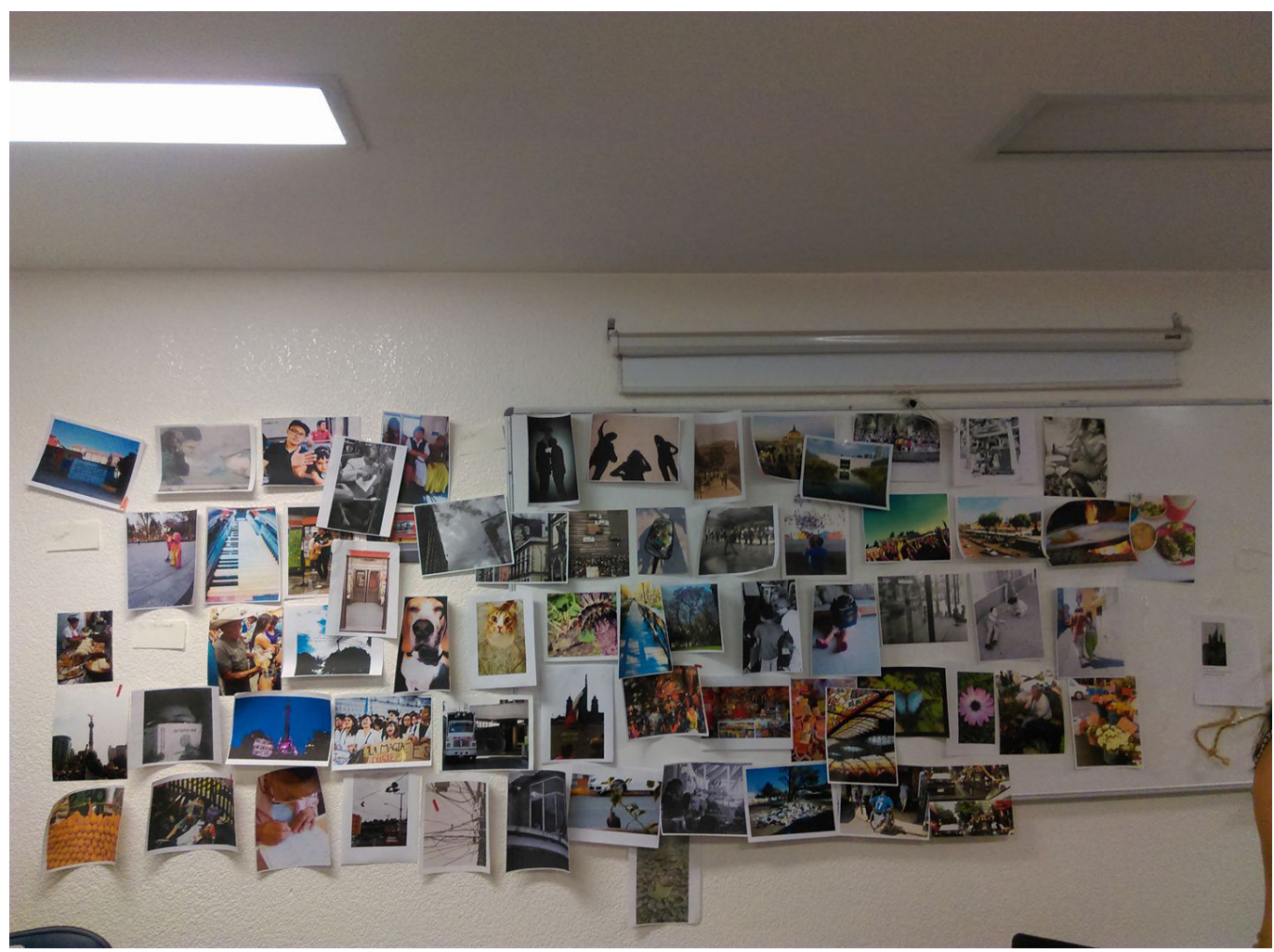

Durante los días en que se presentó la exposición en la galería de la Facultad, los estudiantes tuvieron la oportunidad de interactuar con compañeros de la carrera y miembros de la fFy L, para recabar opiniones e ideas con respecto a su trabajo, así como de los temas representados en las fotografías. Como profesora, una de las cosas que más valoro de estas experiencias es la proyección y visibilidad que pueden tener los estudiantes después de un semestre o un año de trabajo arduo. Hay algo especial cuando el esfuerzo puede compartirse y enriquecerse con la mirada de los otros; de ahí la satisfacción de los que participan en esta actividad. Las artes posibilitan lo colectivo, lo recíproco, lo común, el encuentro, en donde, desde mi perspectiva y experiencia, existe justamente lo educativo. 
Fotografía 6. Ejemplo de invitación utilizada para la inauguración de Cotidianidad-es CDMX.

Fotografía 7. Ejemplo de invitación utilizada para la inauguración de Cotidianidad-es CDMX
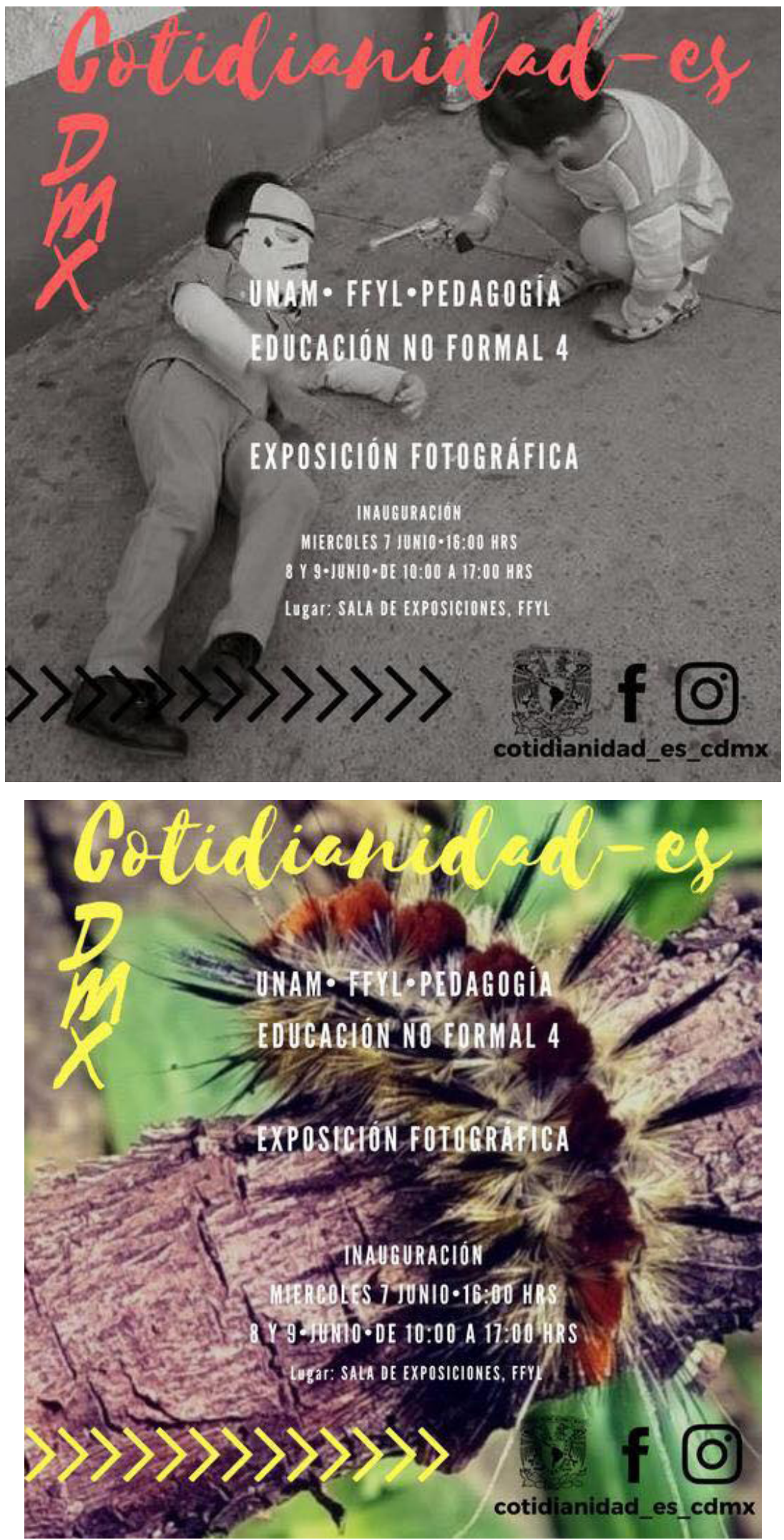


\section{Conclusiones}

Los ejemplos que se exponen en este trabajo representan solamente algunas de las posibilidades con las que se puede trabajar en el aula. Me he enfocado en el caso de la fotografía, pero es importante señalar que la música, el cine y la literatura son también recursos útiles para explorar diferentes temas como los enunciados aquí.

Asimismo, los recorridos culturales y las visitas a museos como otra opción o alternativa de interacción con las artes permiten explorar a la ciudad misma como un valioso espacio de aprendizaje. Las oportunidades parecieran siempre infinitas y, quizá por ello, en la docencia encuentro ese goce o disfrute que, a ratos, nos permite experimentar el placer del artista al crear, imaginar o inventar.

Por último, sería importante destacar el vínculo emocional, profundo y transformador, que se desarrolla en el aula como resultado del trabajo con las artes: ya sea entre el estudiante y el tema en cuestión, o entre los estudiantes mismos. La dinámica docente-alumno también se fortalece: es distinta en términos de participación y colaboración. No tengo la menor duda de que, al ampliar mi propio entendimiento sobre la enseñanza y las dimensiones en las que el aprendizaje puede ocurrir, he podido explorar, aprender y trabajar en el aula con mayor libertad, tratando de componer día a día una relación tanto empática como creativa entre mi pasión por las artes y la docencia propositiva, aquella que genera, en mayor o menor medida, experiencias significativas.

\section{Referencias}

* Arts Council England (s.f.). Inspiring Learning for All. Recuperado de: https://www.artscouncil.org.uk/advice-and-guidance/inspiring-learning-allhome-page.

* Colegio de Pedagogía, fryl-unam (s.f.). Programas de asignatura del plan de estudios 2010 de la licenciatura en Pedagogía. Recuperado de: http://pedagogia.filos.unam. mx/plan-de-estudios-2010/.

- Dewey, J. (1934; 2005). Art as Experience. Nueva York, EE.UU.: Penguin Group.

- Dewey, J. (1938; 1997). Experience and education. Nueva York, EE.UU.: Touchstone.

* Eisner, E. (2004). El arte y la creación de la mente. El papel de las artes visuales en la transformación de la conciencia. Barcelona, España: Paidós.

* Fontainas, A. y Vauxcelles, L. (1922). Histoire Générale de l'Art Francais de la Révolution à nos jours. [tomo II. París. pp. 259-261.]. Recuperado de: https://archive. org/details/histoiregnra02fontuoft/page/n5.

* Hooper-Greenhill, E. (2007). Museums and Education. Purpose, pedagogy and performance. Nueva York, EE.UU.: Routledge. 
* Pastor Homs, M. I. (septiembre-diciembre 2001). Orígenes y evolución del concepto de educación no formal. Revista española de pedagogía, 59 (220). pp. 525545. Recuperado de: https://dialnet.unirioja.es/servlet/articulo?codigo=23701.

* Plazaola, J. (1991). Introducción a la Estética. Historia, teoría, textos. Bilbao, España: Universidad de Deusto.

\section{Cómo citar este artículo}

* Galván Aguilar, Nancy Araceli (2019). Arte y docencia: una composición lúdica. Revista Digital Universitaria (RDU). Vol. 20, núm. 6 noviembre-diciembre. Dol: http:// doi.org/10.22201/codeic.16076079e.2019.v20n6.a8.

Recepción: 29/07/2019. Aprobación: 20/10/2019 